\title{
Ética em publicidade e propaganda no turismo
}

\section{Ethics on publicity and propaganda in the tourism}

\author{
Bárbara Pereira Carmona dos Santos (SANTOS, B. P. C.) ${ }^{*}$ e \\ Cleber Augusto Trindade Castro (CASTRO, A. T.) ${ }^{* *}$
}

\begin{abstract}
RESUMO: Este artigo tem como objetivo apresentar reflexões sobre ética nas estratégias de comunicação por meio da publicidade e propaganda no turismo, levantando aspectos teóricos e práticos da ausência de atitudes éticas nas campanhas publicitárias de destinos, produtos e serviços. O estudo, de caráter exploratório, foi realizado por meio de coleta de dados em bibliografias e documentos com informações sobre a temática abordada. Com a pesquisa, foi possível perceber que há conseqüências negativas da falta de ética na publicidade e propaganda no turismo, tanto para promotores destas campanhas, quanto para os demais agentes envolvidos na atividade turística, acarretando problemas jurídicos ou mercadológicos, como o crime de propaganda enganosa e a distorção da imagem de destinos turísticos no mercado.
\end{abstract}

Palavras-chave: Ética. Comunicação. Publicidade e Propaganda. Marketing. Turismo.

\begin{abstract}
This article has as objective to present reflections on ethics in the strategies of communication by means of the advertising in the tourism, being raised theoretical and practical aspects of the absence of ethical attitudes in the publicity campaigns of destinations, products and services. The study was carried through by means of collection of data in bibliographies and documents with information about the subject matter. With the research, it was possible to perceive that there are negative consequences of the lack of ethics in the advertising in the tourism, as for promoters of these campaigns, as for the others agents involved in the tourist activity, causing legal or marketing problems, as the crime of false propaganda and the distortion of the image of tourist destinations in the market.
\end{abstract}

Keywords: Ethic. Comunication. Publicity and Propaganda. Marketing. Tourism.

\footnotetext{
* Bacharel em Turismo. Pós-graduanda em Marketing e Eventos (UFPA). Gerente de Cobrança na A\&M Credit Cobrança e Telemarketing Ltda. Endereço: Rua Sete, 472 - Conj. Providência - Bairro Maracangalha - Belém - PA. CEP: 66110-101. Telefones: (91) 3257-1908/8173-4593. E-mail: barbara.turismo@gmail.com

** Bacharel em Turismo. Pós-graduando em Estudos Culturais da Amazônia (UFPA). Assistente Técnico em Turismo da Companhia Paraense de Turismo - PARATUR. Endereço: Rua São Miguel, 93 - Bairro Jurunas - Belém - PA. CEP: 66030-550. Telefones: (91) 3272-4741/8158-4408. E-mail: cleber.castro@hotmail.com
} 


\section{INTRODUÇÃO}

As reflexões sobre os princípios e valores que harmonizam a convivência humana em sociedade estão ligadas aos processos de desenvolvimento do conhecimento e da própria humanidade. Atualmente, a ética tem feito parte de discussões filosóficas e de estudos científicos, perpassando inclusive pela formação de profissionais que atuam no mercado capitalista.

A atividade turística, também ligada a esse mercado, utiliza a publicidade e a propaganda como um meio de promover destinos, produtos e serviços, considerando a abrangência e outras vantagens destas estratégias de comunicação. Desse modo, é relevante refletir sobre a importância de atitudes éticas na promoção de campanhas publicitárias no turismo, bem como as consequiências para os diversos agentes envolvidos nestas atividades quando ocorre a ausência dessas atitudes, objetivos deste trabalho.

A pesquisa, de caráter exploratório, foi realizada por meio de levantamento bibliográfico e documental, sendo coletados dados teóricos e exemplos práticos da relação da ética em estratégias de publicidade e propaganda no contexto do marketing turístico.

Este artigo, que apresenta discussões iniciais de uma temática ampla, expõe, no primeiro tópico um apanhado histórico-conceitual da ética, em diferentes perspectivas do pensamento filosófico até um olhar científico e a criação dos "códigos de ética" para atuação profissional. O segundo tópico traz uma abordagem das ações de publicidade e propaganda enquanto estratégias de comunicação ao mercado, relacionando estas ações com a atividade do turismo. O terceiro tópico apresenta uma discussão sobre ética em publicidade e propaganda no turismo, ressaltando alguns problemas práticos de estratégias de comunicação que não consideram princípios éticos socialmente aceitos.

\section{NOÇÕES E PERSPECTIVAS DE ÉTICA}

A concepção de ética está ligada à atividade humana de reflexão sobre os valores da sociedade na qual os indivíduos inserem-se. Dessa maneira, Vázques (1982, p. 24) 
expõe uma noção de ética enquanto "um ramo da filosofia", que procura, assim, compreender costumes, deveres e modos de proceder nas relações humanas em sociedade.

Essa preocupação com as regras que regem a convivência social da humanidade pode ser relacionada com a consideração de Geertz (1989, p. 26) quanto ao fato que o homem produz tais regras, ao mesmo tempo em que necessita da moral para o convívio em grupo, enquanto ser social. Assim, a moralidade da vida social humana está relacionada com a própria cultura, que constrói símbolos e significados às pessoas, em seus diversos grupos sociais.

No pensamento filosófico da Grécia Antiga, Sócrates e Platão representam as reflexões clássicas acerca dos princípios morais da ação humana. Nesse momento histórico, a ética está ligada às questões práticas das ações cotidianas, tendo como objetivo a compreensão do conjunto de procedimentos e idéias que possibilitem a harmonia a (e?) uma boa convivência entre os indivíduos da sociedade.

É atribuída a Sócrates a idéia de que somente ao conhecer o bem o homem age corretamente, e que a ausência do conhecimento do que é bom leva as pessoas a agirem de modo errado. Além disso, a filosofia socrática prega que a identificação e distinção do que é certo ou errado é uma função da faculdade humana da razão (GOLDSCHMIDT, 1963, p. 52).

Vale ressaltar que a noção do que é certo ou errado, bom ou ruim, entre outras antíteses morais, é uma construção e reprodução social que ocorre nos grupos de indivíduos. De acordo com a filosofia socrática, é possível observar que há nesses grupos um processo de aprendizagem dos valores morais, para que o indivíduo passe a agir de maneira correta, seguindo as normas consideradas corretas por aquela sociedade.

A filosofia de Platão entende que os valores e princípios morais da sociedade eram eternos e imutáveis, de acordo com o princípio platônico do "mundo das idéias", onde a responsabilidade do reconhecimento destas regras é da razão (GOLDSCHMIDT, 1963, p. 64).

No percurso histórico da filosofia, vários outros pensadores procuraram refletir sobre as regras regentes do convívio social humano, entre os quais, Kant (2006, p. 24), que propõe um entendimento da natureza moral do homem, que teria tendência ao mal, 
devido à sua natureza animal. Porém, esse comportamento evolui, aproximando-o da bondade, a partir do convívio em sociedade.

Em outra perspectiva, no contexto do desenvolvimento do modo de apreensão do conhecimento, a ética passa a ser objeto de estudo metódico e sistemático de uma ciência moral, passando a constituir "[...] um conhecimento da conduta humana, a partir dos juízos do Bem e do Mal, numa sociedade, numa determinada época" (CASTRO, 1998, p. 15).

Assim, a busca pela compreensão da ética passa a considerar a relativização que existe nos valores morais, que variam entre os grupos sociais e os períodos históricos. No entanto, a objetividade da ciência reduziu as reflexões filosóficas e as abordagens histórico-sociológicas dos valores morais em análises e elaboração de conjuntos de leis e normas de procedimentos, o que tornou a ética um objeto de estudo das ciências jurídicas.

A visão da ética enquanto um conjunto de regras pré-estabelecidas para o comportamento em determinados grupos de pessoas promoveu a criação dos "códigos de ética", especialmente entre as categorias profissionais, com o objetivo de orientar e até mesmo normatizar as atividades destes agentes do mercado. Hoje, as diversas áreas de trabalho, inclusive turismo e publicidade, apresentam um conjunto de regras, orientações e normas para sua atuação no mercado. As regras ligadas às condutas profissionais visam uma boa relação entre a atuação desses trabalhadores, o bem estar e os interesses da sociedade.

No caso do turismo, por exemplo, o profissional envolvido no planejamento e gerenciamento das mais diversas atividades deve primar por responsabilidades econômicas, ambientais e sócio-culturais dos grupos envolvidos nestas atividades. Essa perspectiva é chamada por alguns teóricos de turismo sustentável, que segundo Araújo (2003, p. 80) é uma oposição à ânsia pelos resultados imediatos desta atividade. A sustentabilidade do turismo, portanto, está centrada na postura ética dos profissionais envolvidos, levando em conta valores socialmente aceitos como bons e corretos, para que o turismo não provoque conseqüências consideradas negativas e problemáticas aos grupos sociais envolvidos. 


\section{PUBLICIDADE E PROPAGANDA EM TURISMO}

Os termos "publicidade" e "propaganda" são conceitualmente distintos, sendo o primeiro a comunicação de produtos e serviços voltados para venda e o segundo a propagação de aspectos ideológicos, como os presentes na política e na religião (LAS CASAS, 1993, p. 28). No entanto, essa diferenciação teórica torna-se difícil na prática, já que em sociedades capitalistas, como o Brasil, é possível notar uma "comercialização" de ideologias, bem como a presença de aspectos ideológicos por trás da promoção de produtos, serviços e marcas empresariais, oferecidas no mercado.

Desse modo, publicidade e propaganda são vistas, sem consideráveis distinções dos termos, como as técnicas utilizadas para "criar opinião pública favorável a um determinado produto, serviço, instituição ou idéia" com o objetivo de orientar o comportamento humano das massas num determinado sentido (ASSOCIAÇÃO BRASILEIRA DE AGÊNCIAS DE PUBLICIDADE, 2007, p. 1).

Para Giacomini Filho (2003, p. 224), publicidade e propaganda são modos de comunicação persuasiva, geralmente paga, utilizando meios de comunicação de massa, com identificação de seus promotores. $\mathrm{O}$ autor expõe ainda que, pela abrangência das campanhas publicitárias, este modo de comunicação pode ser usado para tornar uma marca organizacional mais conhecida, para divulgar informações sobre produtos, serviços ou idéias, além de captar novos clientes ou reafirmar o consumo dos clientes atuais.

A campanha publicitária, no contexto dos negócios, segundo Lopes (2007, p. 6), "é a materialização dos objetivos e estratégias de comunicação", inserida nos modos de gestão atual, onde os interesses e necessidades dos consumidores são identificados, anteriormente à elaboração de produtos e serviços a serem ofertados, bem como para a adequação das estratégias de comunicação que alcancem tais consumidores, para o sucesso mercadológico das organizações. Essa perspectiva de gestão é o que Kotler (2000, p. 35) chama de marketing.

Por estar relacionado com a dinâmica do mercado capitalista, o turismo também é planejado e administrado como uma atividade voltada à satisfação dos consumidores, neste caso, turistas. Para alcançar esse objetivo são aplicadas estratégias de marketing, 
inclusive com ações de publicidade e propaganda, promovidas por agentes ligados a organizações privadas ou ao poder público (LOPES, 2007, p. 8).

Alguns teóricos afirmam que existe um "produto" específico oferecido pela cadeia produtiva do turismo e consumido pelos turistas. Este produto congrega elementos tangíveis e intangíveis, entre serviços, facilidades e estruturas, comercializados como produtos turísticos. Este conjunto de elementos é caracterizado por características como as de, não poder se materializado, embalado, ou estocado, como os produtos industrializados, o que ressalta as especificidades da produção e comercialização do turismo (RUSCHMANN, 1990, p. 26; LOPES, 2007, p. 8; ANSARAH, 2001, p. 15).

Entre os elementos constituintes do produto turístico estão os serviços de transporte, hospedagem, alimentação e entretenimento, além dos atrativos turísticos, que são os elementos que motivam os turistas a realizarem suas viagens a determinado destino (BARRETTO, 1996, p. 72). Dessa maneira, nas estratégias de comunicação no mercado turístico constam especialmente informações sobre os atrativos turísticos dos locais a serem visitados, bem como das facilidades e serviços à disposição dos turistas.

É para o consumo do produto turístico que os turistas deslocam-se, e é para a comercialização deste produto que o marketing turístico é planejado e implementado por organizações públicas ou privadas. Assim, as técnicas de publicidade e propaganda, no contexto da atividade turística, são meios de informar e persuadir turistas potenciais, com impessoalidade à distância, para empreenderem viagens e consumir os elementos a elas relacionados (RUSCHMANN, 1990, p. 61).

\section{A Ética (E SUA AUSÊNCIA) EM PUBLICIDADE E PROPAGANDA NO TURISMO}

Por levar informações persuasivas sobre um destino turístico, aos mais diversos núcleos emissores de turistas, a propaganda tem um elevado grau de importância para o turismo. No entanto, cabe destacar que, além da influência de movimentação do fluxo turístico, as estratégias de comunicação presentes nas campanhas publicitárias, em especial fora de parâmetros éticos, podem ter conseqüências indesejadas, seja pelos seus 
promotores - empresários ou governos -, seja pela comunidade receptora de tal fluxo ou pelo próprio turista.

Uma das consequiências negativas acontece quando prevalecem interesses e objetivos unilaterais das organizações, ou mesmo por falta de pleno conhecimento e profissionalismo, fazendo com que as ações de publicidade e propaganda não venham a considerar os princípios éticos de "jamais lançar mão da inverdade; jamais disseminar a desonestidade e o vício" (ASSOCIAÇÃO BRASILEIRA DE AGÊNCIAS DE PUBLICIDADE, 2007, p. 3). A ausência de informações verídicas nas ações de publicidade e propaganda para o turismo leva à motivação de uma viagem ou à escolha de determinado produto ou serviço com base em desejos ou expectativas que não serão satisfeitas pelo turista.

Além de desrespeitar a função informativa da publicidade e da propaganda, o erro supracitado é uma prática considerada criminosa na sociedade brasileira, prevista no artigo $6^{\circ}$ da lei 8.078 (BRASIL, 2008, p. 3), onde são considerados direitos básicos do consumidor a divulgação adequada de produtos e serviços, com informações claras e verídicas, estando protegido contra a publicidade enganosa e abusiva.

Vale ressaltar que não é apenas o turista que sofre as conseqüências oriundas das práticas errôneas ou abusivas das estratégias de comunicação em turismo. O local que recebe turistas, chamado de destino turístico, também pode sofrer conseqüências indesejadas por falhas na publicidade e propaganda, que muitas vezes perduram por um longo período.

Essas conseqüências afetam o que Dias (2003, p. 200) conceitua como imagem, que corresponde à percepção do consumidor sobre um produto, instituição, marca, empresa ou pessoa, podendo ou não corresponder a realidade, construída pelas informações que chegam a este consumidor. Portanto, a publicidade turística tem, também, responsabilidade de construir essa imagem.

Estudos mostram que o Brasil, enquanto destino turístico sofreu uma consolidação da imagem com "exóticos paraísos sexuais", no mercado internacional, o que contribuiu para o crescimento da exploração sexual através do turismo. Hoje, institucionalmente o país trabalha, nas ações de publicidade e propaganda, a diversidade cultural e as paisagens naturais para tentar reverter a imagem indesejada que se consolidou ao longo do tempo (TURISMO SUSTENTÁVEL E INFÂNCIA, 2007). 
É possível notar, portanto, que uma falha no modo como são realizadas as campanhas publicitárias pode trazer efeitos negativos para a imagem mercadológica de destinos, produtos ou serviços, na dinâmica do turismo, mesmo que essas consequiências nem sempre sejam propositais.

Outro problema advindo de erros no planejamento das ações de comunicação por meio da publicidade e da propaganda é a divulgação de atrativos turísticos sem infra-estruturas para garantir a integridade destes atrativos diante da demanda por visitação gerada ou sustentada por estas estratégias de comunicação.

Segundo Cardozo e Caciattori (2006, p. 9), a divulgação de atrativos turísticos, sejam naturais ou culturais, que não apresentam estrutura para o desenvolvimento da atividade turística impacta negativamente nestes atrativos, contribuindo para a depredação, e em alguns casos até a destruição, de patrimônios naturais e culturais.

O levantamento e o debate sobre consequiências das ações de comunicação na atividade turística são amplos e requerem uma constante reflexão sobre a temática. Todavia, os exemplos aqui apresentados são suficientes para demonstrar que atitudes éticas são prescindíveis para a obtenção de ganhos com a atividade, para os diversos agentes envolvidos.

Como ressalta Lopes (2007, p. 4), no planejamento do desenvolvimento da atividade turística "ética e estética devem caminhar juntas". Assim, é possível o fomento de ganhos econômicos e sociais.

\section{CONSIDERAÇÕES FINAIS}

As ações de publicidade e propaganda são importantes para a atividade turística, por possibilitar a abrangência massiva de mercados-alvo, mesmo em lugares geograficamente distantes. No entanto, são conhecidas consequiências negativas às instituições e pessoas envolvidas nessa atividade, causadas pela ausência da ética nas estratégias de comunicação.

Do ponto de vista legal, a propaganda que veicula informações falsas e induz o turista ao erro no momento da escolha por destinos, produtos ou serviços é caracterizada como crime de publicidade enganosa, com punições judiciais previstas em lei. Além 
disso, na dinâmica do mercado turístico, um destino pode captar um tipo de turista diferente do público desejado, por falhas na estratégia de comunicação, como no caso de visitantes que contribuem para a exploração sexual no país, ou que são agentes depredadores do patrimônio cultural e natural, devido a falta de estruturas para receber estes turistas atraídos pela propaganda.

Assim, a ética, enquanto limitação individual para o bem coletivo deve estar presente nas ações de publicidade e propaganda, para que a relação que existe entre organizações públicas e privadas, a comunidade local e os turistas ocorra de maneira harmoniosa, no desenvolvimento da atividade turística.

Outrossim, cabe aos profissionais envolvidos na comunicação e no turismo a reflexão quanto aos meios que garantam o sucesso de agentes interessados em obter lucros com o turismo, sem que isso aconteça em detrimento dos direitos que os turistas e as comunidades receptoras têm.

Portanto, é relevante o aprofundamento do debate ora apresentado, tanto no meio acadêmico quanto no mercado, para que o turismo ocorra cada vez mais com profissionalismo e, principalmente, com ética.

\section{REFERÊNCIAS}

ANSARAH, M. G. dos R. Teoria geral do turismo. In: (org.). Turismo. Como aprender, como ensinar. São Paulo: Editora SENAC São Paulo, 2001.

ARAUJO, C. Ética e qualidade no turismo do Brasil. São Paulo: Atlas, 2003.

ASSOCIAÇÃO BRASILEIRA DE AGÊNCIAS DE PUBLICIDADE. Código de Ética dos profissionais da propaganda, outubro de 1957. Disponível em: < http://www.abap.com.br/legislacao/arquivos/>. Acesso em: 17/12/2007.

ASSOCIAÇÃO BRASILEIRA DE BACHARÉIS EM TURISMO. Código de ética do bacharel em turismo. Disponível em: <http://www.abbtur.org.br>. Acesso em: $16 / 3 / 2008$.

BARRETTO, M. Planejamento e organização em turismo. Campinas: Papirus, 1996.

BRASIL. Lei n. 8.078, de 11 de setembro de 1990. Disponível em: <http://www.planalto.gov.br>. Acesso em: 10/4/2008. 
CARDOZO, M. L.; CACIATTORI, P. R. R. Comunicação integrada de marketing e impactos turísticos no PETAR. (Anais do XXIX Congresso Brasileiro de Ciências da Comunicação). Brasília: UnB, 2006.

CASTRO, I. E. Turismo e ética. In: CORIOLANO, L. N. M. T. (Org.). Turismo com ética. Fortaleza: FUNECE, 1998.

DIAS, R. Planejamento do turismo. Política e desenvolvimento do turismo no Brasil. São Paulo: Editora Atlas, 2003.

GEERTZ, C. A interpretação das culturas. Rio de Janeiro: Editora Guanabara, 1989.

GIACOMINI FILHO, G. Marketing: conteúdo, didática e perspectiva. In: TRIGO, L. G. G. (org.). Turismo. Como aprender, como ensinar. São Paulo: Editora SENAC São Paulo, 2003.

GOLDSCHMIDT, V. A religião de Platão. São Paulo: Difusão Européia do Livro, 1963.

GONÇALVES, C. M. Ética e persuasão na publicidade dos rótulos de embalagens. Revista Cenários da Comunicação. São Paulo: UNINOV, 2004.

KANT, I. A Religião nos limites da simples razão. São Paulo: Escala Educacional, 2006.

KOTLER, P. Administração de marketing: a edição do novo milênio. São Paulo: Prentice Hall, 2000.

LAGE, B. H. G. Comunicação de massa e turismo. In: LAGE, B. H. G.; MILONE, P. C. (orgs.). Turismo teoria e prática. São Paulo: Atlas, 2000.

LAS CASAS, A. L. Marketing: conceitos, exercícios e casos. São Paulo: Atlas, 1993.

LOPES, D. V. Comunicação e turismo: nuances e estratégias. Disponível em: <http://www.nobel.br/>. Acesso em: 22/3/2007.

RUSCHMANN, D. van de M. Marketing turístico: um enfoque promocional. Campinas: Papirus, 1990.

TURISMO SUSTENTÁVEL E INFÂNCIA. Proteja a criança e o adolescente da exploração sexual no turismo. Vídeo institucional. Brasília: UnB, 2007.

VÁZQUEZ, A. S. Ética. Rio de Janeiro: Civilização Brasileira, 1982.

Recebido em: 10 de agosto de 2007

Aprovado em: 10 de setembro de 2007 